\title{
EDUCAÇÃO AMBIENTAL E OS SISTEMAS DE GESTÃO AMBIENTAL NO DESAFIO DO DESENVOLVIMENTO SUSTENTÁVEL
}

\author{
Larissa Azambuja Alcântara ${ }^{1}$, Maria Clara Araujo Silva ${ }^{1}$, Toshio Nishijima $^{2}$ \\ ${ }^{1}$ Aluna do Mestrado em Engenharia Agrícola, UFSM, E-mail:la engamb@yahoo.com.br \\ ${ }^{1}$ Aluna do Mestrado em Engenharia Agrícola, UFSM, E-mail:mariaclarsi@hotmail.com \\ ${ }^{2}$ Prof. Dr., DER/CCR/UFSM, Orientador,E-mail:toshionishijima@gmail.com
}

\section{Resumo}

Atualmente, a Educação Ambiental vem assumindo uma crescente importância na sociedade. Por meio do desenvolvimento sustentável e a inserção de práticas educacionais voltadas para a conservação do meio ambiente busca-se uma melhor qualidade de vida para a sociedade, onde esta deve-se manter em equilíbrio com o ecossistema. Este trabalho justifica-se por expor conceitualmente a interação entre dois aspectos fundamentais para a sustentabilidade e equilíbrio do ecossistema, a Educação Ambiental aliada à Gestão Ambiental. A Educação Ambiental deve ser abordada de forma sistemática e transversal, em todos os níveis de ensino, assegurando a presença da dimensão ambiental de forma interdisciplinar nos currículos escolares. Esta prática proporciona a mudança de valores e o aperfeiçoamento de habilidades, condições necessárias para obter um equilíbrio entre os cidadãos e o meio natural. Deste modo, a Educação Ambiental pode ser vista como uma prática sócio-educativa integrada, contínua e permanente, com o intuito de informar, sensibilizar e, comprometer a sociedade e os gestores públicos, sobre a importância de se conhecer e diminuir os problemas ambientais. Juntamente com a Educação Ambiental, os sistemas de Gestão Ambiental vem ganhando um espaço crescente no meio empresarial. O aumento da consciência ecológica é visível em diferentes níveis e setores da sociedade. Com isso, a aplicação da Gestão Ambiental tem como objetivo criar técnicas, planejar, organizar e administrar atividades econômicas e sociais de forma a utilizar de maneira racional os recursos naturais, bem como realizar o cumprimento da legislação ambiental. Apresenta caráter multidisciplinar, pois, profissionais dos mais diversos campos podem atuar na área, desde que devidamente habilitados. Assim, tem-se a relação entre a Educação Ambiental e a Gestão Ambiental, pois, estas agindo paralelamente tornam-se instrumentos essenciais para manter o equilíbrio entre o meio ambiente e a sociedade. Não basta apenas contarmos com sistemas de gestão eficientes e, sim colocarmos a Educação Ambiental como ponto de partida, para posteriormente buscarmos técnicas e soluções em benefício do meio natural. Desta maneira, a Educação Ambiental atuando como um instrumento de Gestão Ambiental pode se tornar eficaz e eficiente, por meio da mudança de valores, conceitos e comportamentos. E, aliada a outros instrumentos econômicos de controle vem a contribuir para a construção de uma sociedade autosustentável, priorizando o equilíbrio do meio ambiente.

Palavras-chave: Educação Ambiental - Gestão Ambiental - Desenvolvimento Sustentável. 


\title{
Revista Eletrônica em Gestão, Educação e Tecnologia Ambiental
}

REGET/UFSM (e-ISSN: 2236-1170).

\begin{abstract}
Currently, Environmental Education has assumed a growing importance in society. Through the inclusion of sustainable development and educational practices for the conservation of the environment we seek to better quality of life for society, where it should be kept in balance with the ecosystem. This work is justified conceptually by considering the interaction between two fundamental aspects for the sustainability and balance of the ecosystem, together with the Environmental Education Environmental Management. Environmental education should be approached in a systematic and cross at all levels of education, ensuring the presence of the environmental dimension of interdisciplinary curricula. This practice provides the change of values and skills upgrading, conditions necessary to obtain a balance between the citizens and the natural environment. Thus, environmental education can be seen as a socio-educational practice integrated, continuous and permanent, in order to inform, sensitize and compromising society and policy makers on the importance of understanding and reduce environmental problems. Together with the Environmental Education, Environmental Management Systems has gained an increasing space in the business. Increased environmental awareness is visible at different levels and sectors of society. Thus, the application of Environmental Management aims to create techniques, plan, organize and manage economic and social activities in order to rationally use natural resources as well as carry out compliance with environmental legislation. Presents multidisciplinary therefore professionals from diverse fields can act in the area, if properly enabled. Thus, there is the relationship between Environmental Education and Environmental Management, therefore, acting alongside these instruments become essential to maintain the balance between the environment and society. It is not enough to count on efficient management systems and, yes put environmental education as a starting point for further technical and seek solutions for the benefit of the natural environment. Thus, the Environmental Education acting as an instrument of environmental management can become effective and efficient by changing the values, concepts and behaviors. And, combined with other instruments of economic control is contributing to the construction of a self-sustainable, prioritizing the environmental balance.
\end{abstract}

Keywords: Environmental Education - Environmental Management - Sustainable Development.

\section{Introdução}

Atualmente, a Educação Ambiental vem assumindo uma crescente importância na sociedade, principalmente pela urgência de reversão do quadro de deterioração ambiental. A Educação Ambiental deve ser desenvolvida como uma prática sócio-educativa integrada, contínua e permanente, mantendo-se em todos os níveis e modalidades do ensino formal (JACOBI, 2003). Esta abordagem aponta para um novo modelo de desenvolvimento, fornecendo informações para que haja a conscientização ambiental, o comprometimento e por meio da participação da população aliada aos gestores públicos com a finalidade de estabelecer um processo permanente, com o intuito de conhecer e minimizar a problemática ambiental em âmbito local.

Deste modo, este trabalho justifica-se por expor conceitualmente a interação entre dois aspectos fundamentais para a sustentabilidade e equilíbrio do ecossistema, a Educação Ambiental aliada à Gestão Ambiental. 


\section{Objetivo geral}

Este trabalho visa apresentar de forma conceitual a interrelação da Educação Ambiental com os Sistemas de Gestão Ambiental.

\subsection{Objetivos específicos}

- Expor a importância da Educação Ambiental, numa abordagem conceitual;

- Apresentar aspectos da Gestão Ambiental;

- Discutir a Educação Ambiental como fator de sensibilização para a Gestão Ambiental.

\section{Referencial teórico}

Por meio do desenvolvimento sustentável e a inserção de práticas educacionais voltadas para a conservação do meio ambiente, busca-se uma melhor qualidade de vida para a sociedade, onde esta deve-se manter em equilíbrio com o ecossistema. O Capítulo VI art. 225 da Constituição Federal estabelece que "todos têm direito ao meio ambiente ecologicamente equilibrado, bem de uso comum do povo e essencial à sadia qualidade de vida, impondo-se ao poder público e à coletividade o dever de defendê-lo e preservá-lo para as presentes e futuras gerações". Assim, busca-se tornar essencial o direito de todos de viver e conviver em um meio ambiente ecologicamente equilibrado, e com isso, cabe ao Poder Público e à coletividade a obrigação por sua defesa e preservação. Com isso, trata-se de compreender, buscar novos padrões e mudanças, construídos coletivamente, através do comprometimento da sociedade em sua relação com o meio natural.

A atuação da Gestão Ambiental tem sua importância no desenvolvimento sustentável, pois esta:

prima pelo desenvolvimento de uma visão integrada do meio ambiente, fundamentado numa abordagem científica e analítica para diagnosticar, gerar dados e propor soluções que minimizem os impactos ambientais causados ao meio natural pelas atividades humanas (DIAS, 2006).

A Educação Ambiental pode ser abordada como um instrumento de Gestão Ambiental, pois essa nova área de conhecimento e ocupação profissional prioriza a mudança de valores e de comportamento da sociedade, buscando o desenvolvimento de atitudes que valorizem a postura ética e cidadã quanto às questões ambientais, de uma maneira, contínua e permanente (SILVA, s.d.)

\subsection{Conceituando a Educação Ambiental}

A Educação Ambiental:

contribui para a compreensão fundamental da relação e interação da humanidade com todo o ambiente e fomenta uma ética ambiental pública a respeito do equilíbrio ecológico 
ALCÂNTARA et al., v(5), n5, p. 734 - 740, 2012.

Revista Eletrônica em Gestão, Educação e Tecnologia Ambiental

REGET/UFSM (e-ISSN: 2236-1170).

e da qualidade de vida, despertando nos indivíduos e nos grupos sociais organizados o desejo de participar da construção de sua cidadania (ZITZKE, 2002).

No Brasil, a preocupação com conservação do meio ambiente é exposta de forma clara e objetiva perante o art. 225 da Constituição Federal, onde este diz que: "todos têm direito ao meio ambiente ecologicamente equilibrado, bem de uso comum do povo e essencial à sadia qualidade de vida, impondo-se ao poder público e à coletividade o dever de defendê-lo e preservá-lo para as presentes e futuras gerações". Assim, busca-se tornar essencial o direito de todos de viver e conviver em um meio ambiente ecologicamente equilibrado, em ações conjuntas entre o Poder Público e da sociedade pela defesa e preservação ambiental.

Além da Constituição Federal podemos referenciar a Lei 9.795 de 27 de abril de 1999, esta institui a Política Nacional de Educação Ambiental, abordando especificamente questões importantes sobre a Educação Ambiental. Segundo o art. 1ำ, entende-se por Educação Ambiental:

os processos por meio dos quais o indivíduo e a coletividade constroem valores sociais, conhecimentos, habilidades, atitudes e competências voltadas para a conservação do meio ambiente, bem de uso comum do povo, essencial à sadia qualidade de vida e sua sustentabilidade.

Em complemento, o art. $2^{\circ}$ diz que: "a educação ambiental é um componente essencial e permanente da educação nacional, devendo estar presente, de forma articulada, em todos os níveis e modalidades do processo educativo, em caráter formal e não-formal".

A questão da formalidade ou da informalidade da Educação Ambiental depende de como e onde ela será abordada. Destaca-se que:

A Educação Ambiental traz consigo uma série de práticas e ações, que ultrapassam as barreiras ou fronteiras existentes entre a educação-formal e não-formal, estabelecendo vínculos e ligações, integrando a escola e a comunidade em torno dela (Kist, 2009 apud Carvalho, 2004).

A Educação Ambiental deveria ser colocada de forma sistemática e transversal, em todos os níveis de ensino, assegurando a presença da dimensão ambiental de forma interdisciplinar nos currículos das diversas disciplinas e das atividades escolares.

Para Pádua e Tabanez (1998), a educação ambiental proporciona a mudança de valores e o aperfeiçoamento de habilidades, condições necessárias para obter um equilíbrio entre os cidadãos e o meio natural. Deste modo, a Educação Ambiental pode ser vista como uma prática sócio-educativa integrada, contínua e permanente, com o intuito de informar, sensibilizar, conscientizar e, comprometer a sociedade, bem como os gestores públicos, sobre a importância de se conhecer e diminuir os problemas ambientais em escala local.

Assim, a Educação Ambiental deve ser vista, acima de tudo, como uma mudança de atitudes e, ser colocada como um ato político voltado para a transformação social, considerando a necessidade da sustentabilidade ecológica, social e econômica, buscada através de intervenções integradoras e coordenada.

\subsection{Sistemas de Gestão Ambiental}

A Gestão Ambiental vem ganhando um espaço crescente no meio empresarial. $O$ aumento da consciência ecológica se faz visível em diferentes níveis e setores da sociedade, 
englobando empresas distintas e instituições de ensino (TAUCHEN, 2006). Corazza (2003) apud Nilsson (1998) "coloca que a Gestão ambiental envolve planejamento, organização, e orienta a empresa a alcançar metas [ambientais] especificas". Um aspecto relevante da gestão ambiental é que sua introdução requer decisões nos níveis mais elevados da administração e, portanto, envia uma clara mensagem à organização de que se trata de um compromisso corporativo.

Assim podemos considerar que, a aplicação da Gestão Ambiental tem como objetivo criar técnicas, planejar, organizar e administrar atividades econômicas e sociais de forma a utilizar de maneira racional os recursos naturais, bem como realizar o cumprimento da legislação ambiental. Apresenta caráter multidisciplinar, pois, profissionais dos mais diversos campos podem atuar na área, desde que devidamente habilitados. Necessita de uma tomada de decisões em curto prazo para garantir a conservação e preservação da biodiversidade e, consequentemente minimizar os impactos ambientais provocados pelas ações humanas.

À medida que a sociedade vai se conscientizando da necessidade de se preservar o meio ambiente, começa a surgir um novo enfoque de pensamento, onde de intensifica a pressão sobre as empresas, para que estas busquem alternativas de desenvolver suas atividades econômicas modo sustentável. Com isso, podemos citar as ISO's, que são normas desenvolvidas pela International Organization for Standardization (ISO) e, que estabelecem diretrizes sobre a área de gestão ambiental dentro de empresas.

A NBR ISO 14000 é a norma através da qual, as empresas ou interessados se autodeclararão em conformidade ou buscarão certificação junto a terceiros. A norma descreve os requisitos básicos de um Sistema de Gestão Ambiental (MOURA, 2003). Desta forma, desenvolveu-se a norma ISO 14001 que tem por finalidade:

equilibrar a proteção ambiental e a prevenção de poluição com as necessidades socioeconômicas, estabelecendo as diretrizes básicas para o desenvolvimento de um sistema que gerencie a questão ambiental dentro de uma determinada empresa, ou seja, um Sistema de Gestão Ambiental (ISO 14001, 2004).

Os Sistemas de Gestão Ambiental (SGA) são definidos segundo a NBR ISO 14001, como a parte do sistema de gestão que compreende a estrutura organizacional, as responsabilidades, as práticas, os procedimentos, os processos e recursos para aplicar, elaborar, revisar e manter a política ambiental da empresa. Desta forma, têm-se várias certificações para que empresas apliquem o pensamento ambiental e sustentável, por meio de técnicas e soluções. Sendo assim, a "família ISO14000" é de suma importância, pois, atestam que uma determinada empresa executa suas atividades com base nas normas da Gestão Ambiental, visando o uso racional dos recursos naturais, renováveis ou não.

De um modo geral, a Gestão Ambiental é consequência natural da evolução do pensamento da humanidade em relação à utilização dos recursos naturais, é a união de técnicas, conhecimentos, tanto por parte da sociedade, bem como do setor empresarial, em busca de soluções e alternativas para manter o equilíbrio ambiental, reduzindo ou recuperando a degradação do meio natural.

\subsection{Interrelação da Educação Ambiental com os Sistemas de Gestão Ambiental}

Diante dos conceitos abordados acima percebemos a clara relação entre a Educação Ambiental e a Gestão Ambiental, pois, estas agindo paralelamente tornam-se ferramentas essenciais para manter o equilíbrio entre o meio ambiente e a sociedade. Para se ter um bom 
Sistema de Gestão Ambiental é preciso, primeiramente, ter em mente, de forma clara e objetiva o que é a Educação Ambiental e, qual sua verdadeira importância para a sustentabilidade.

Ribeiro (2007), diz que "a educação ambiental não só precede, mas permeia os outros instrumentos de gestão ambiental". Ainda segundo a autora, percebe-se a interação dos instrumentos de gestão não somente no sentido de incentivar a participação da comunidade e, até facilitar a implementação dos instrumentos financeiros, de comando e controle, como também no sentido de tornar eficazes as ações de educação ambiental, que sozinhas perdem a razão de ser. Deste modo, não basta apenas contarmos com sistemas de gestão eficientes e, sim colocarmos a Educação Ambiental como ponto de partida, ferramenta de conhecimento dos problemas ambientais, para posteriormente buscarmos técnicas e soluções em benefício do meio natural.

Conforme Almeida (1994), a educação ambiental "pode ser concebida pela economia neoclássica, como um investimento ou gasto governamental geral que dá suporte à implementação de políticas de comando e controle". A utilização da Educação Ambiental, como um instrumento de gestão, exige conhecimento, esforço e recursos físicos, humanos e financeiros, para assim atuar de forma eficaz na sociedade.

A Educação Ambiental, sendo um instrumento de Gestão Ambiental, caracterizado como de persuasão, tem a possibilidade de ampliar os horizontes da atuação, replicando os conceitos aprendidos para diferentes situações de proteção ao meio ambiente (RIBEIRO, 2007).

\section{Metodologia}

A metodologia utilizada para esta pesquisa foi mediante o emprego de artigos científicos e monografias obtidos em meio digital. Este material foi utilizado para o desenvolvimento e fundamentação teórica deste artigo, a fim de expor conceitualmente a relação entre os dois temas.

\section{Conclusão}

A Gestão Ambiental é de grande valia para o desenvolvimento sustentável, pois apresenta diferentes técnicas em benefício ao meio natural, mas deve-se ressaltar que, não basta apenas contarmos com sistemas de gestão eficientes e sim, abordarmos práticas de Educação Ambiental como ponto de partida, expondo conhecimentos e alternativas para minimizar os problemas ambientais e, para posteriormente aplicarmos técnicas e soluções que cabem aos Sistemas de Gestão Ambiental.

Desta maneira, a Educação Ambiental atuando como um instrumento de Gestão Ambiental pode se tornar eficaz e eficiente, por meio da mudança de valores, conceitos e comportamentos. E, aliada a outros instrumentos econômicos de controle vem a contribuir para a construção de uma sociedade auto-sustentável, priorizando o equilíbrio do meio ambiente. 
ALCÂNTARA et al., v(5), n5, p. 734 - 740, 2012.

\section{Referências bibliográficas}

ALMEIDA, L.T. Instrumentos de Política Ambiental: debate internacional e questões para o Brasil. Campinas, Unicamp.IE, 1994.

ASSOCIAÇÃO BRASILEIRA DE NORMAS TÉCNICAS. NBR ISO 14001: Sistemas da gestão ambiental - Requisitos com orientações para uso. Rio de Janeiro, 2004.

Constituição Federal Capítulo VI - DO MEIO AMBIENTE (ART. 225). Disponível em:<http://alerjln1.alerj.rj.gov.br/constfed.nsf/16adba33b2e5149e032568f60071600f/62e3ee4d23ca92ca032565620 0708dde?OpenDocument> Acesso em: 21 jul de 2011.

CORAZZA, Rosana I. Gestão Ambiental e mudanças da estrutura organizacional. RAE-eletrônica, v. 2, n. 2, juldez/2003. Editora: Fundação Getulio Vargas - Escola de Administração de Empresas de São Paulo.

DIAS, Reinaldo. Gestão Ambiental: Responsabilidade Social e Sustentabilidade. São Paulo: Atlas, 2006.

JACOBI, Pedro. Educação Ambiental, Cidadania e Sustentabilidade. Cadernos de Pesquisa, n. 118, p. 189-205, março/ 2003.

Kist, Anna C.F. “A água numa perspectiva crítica da Educação ambiental”: uma análise a partir da III Conferência Nacional Infanto-Juvenil pelo meio ambiente. Monografia de Especialização em Educação Ambiental, Santa Maria. 2009.

Lei 9.795/99. Política Nacional de Educação Ambiental. Disponível em:<

http://www.planalto.gov.br/ccivil_03/leis/I9795.htm> Acesso em: 22 jul de 2011.

MOURA, Luiz A. R. de. O que é ISO 14000. Disponível em:

<http://www.gestaoambiental.com.br/articles.php?id=10\&page=1> Acesso em: 24 jul de 2011.

PÁDUA, S.; TABANEZ, M. (orgs.). Educação ambiental: caminhos trilhados no Brasil. São Paulo: Ipê, 199

RIBEIRO, Lore Margarete M. Educação Ambiental: uma análise como instrumento de gestão ambiental. E-Revista Facitec, v.1 n.1, Art.2, março. 2007.

SILVA, et al. Educação como Instrumento de Gestão Ambiental numa perspectiva transdisciplinar. São Paulo, s.d.

ZITZKE, V. A. Educação Ambiental e Ecodesenvolvimento. Revista Eletrônica do Mestrado em Educação Ambiental. v. 9, 2002. Disponível em:<http://www.fisica.furg.br/mea/remea/vol9/a13art16.pdf. Acesso em: 22 jul de 2011. 